\title{
Impact a circular cylinder with a flat on an elastic layer
}

\author{
Vladislav Bogdanov \\ Progressive Research Solutions Pty. Ltd. \\ Fontenoy Rd, Macquarie Park83/35, Sydney, Australia 2113 \\ vladislav_bogdanov@hotmail.com, orcid.org/0000-0002-3424-1801
}

Received on 06.09.2018, accepted after revision on 02.12.2018

DOI: $10.31493 /$ tit1812.0302

\begin{abstract}
In the work the comparison of the results of solving two plane problems is performed: the impact of a circular cylinder with a plane platform parallel to the cylinder axle (the flat) with an elastic layer and a second - plane strain state of nonstationary interaction of a circular cylinder with a flat with an elastic layer in a purely elastic and elastic-plastic mathematical formulation corresponding. The first contact occurs along the plane of the flat. A good coincidence of the results of the second problem at an elastic stage with the results of the first problem is shown. In the author's works a new approach was developed to solve plane and tree dimension problems of impact and non-stationary interaction in an elastoplastic formulation. The crack growing was simulated using an elastoplastic mathematical model. The numerical solution was obtained using the finite difference method scheme.

The use of an elastic-plastic formulation makes it possible: 1) determine the stress-strain state at the points determined by the partitioning grid of the computational domain, not only on the surface; 2) to give a reliable description of the development of plastic deformations - the stage corresponding to plasticity is a continuation of the elastic stage; $3)$ reliably determine the destruction toughness. A method has been developed for calculating plastic strain fields and destruction toughness of the material using the solutions of dynamic plane problems of the stress-strain state in an elastoplastic formulation taking into account possible material unloading; 4) to verify and calibrate the solution of problems in an elastoplastic formulation for the first steps by time
\end{abstract}

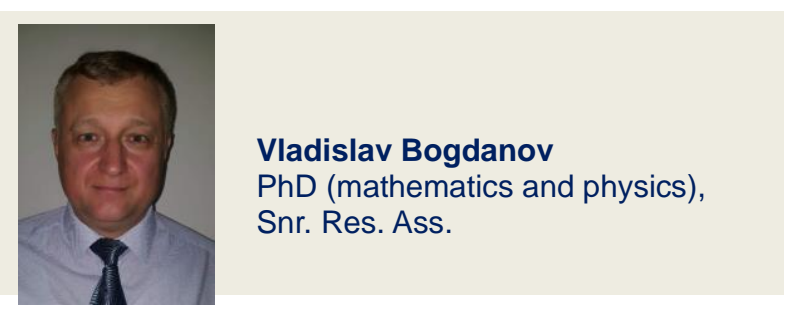

when the deformation process is elastic, it is convenient to use the solution of the corresponding elastic problem.

Keywords: impact, elastic, elastic-plastic, layer, plane problem, hard cylinder.

\section{INTRODUCTION}

The approach [3 - 7] for solving the dynamic problems, developed by V.D. Kubenko makes it possible to determine the stress-strain state only on the surface of the medium into which the drummer penetrates. In addition, this approach does not allow to investigate the impact of elastic shells of S.P. Tymoshenko type. To the equations describing the dynamics of the shell, the Laplace transform and the development to Fourier trigonometric series are applied. After returning to the space of the originals and using theorem on convolution in integral expressions, the components of the series of normal and tangential displacements of the median surface of the shells of the S.P. Tymoshenko type some nuclei will have asymptotic $O(1)$. Therefore, with increasing 
order of a reduced system of integral equations of Volterra of the second kind [1 - 3], the determinant of the system of linear algebraic equations will be indefinitely enlarged - it will seem that the matrix of this system is weak conditioned. However, if use shell of Kirchhoff - Love type [4 - 7], then when solving problems of impact, the convergence of the solution will be guaranteed. This led [8 - 12] to the expediency of developing other mathematical approaches and models. In [13 17], a new approach to solving problems of impact and non-stationary interactions in an elastic-plastic mathematical setting was developed [18-21].

In this paper it was compared the results of solving two plane problems of the motion of a circular rigid cylinder with a flat on an elastic layer: 1) impact within a strictly elastic model; 2) no stationary interaction in elastoplastic formulation. At the initial moment the circular cylinder contacted with the surface of the layer along the plane of the flat.

\section{PROBLEM FORMULATION}

Firstproblem. Thehardcircularcylinderwitht heflatmovesverticallydownperpendiculartothes urfaceoftheelasticlayer $0 \leq z \leq H$ and contacts it along the lane $\{|x| \leq d ; z=0\}$, where $d-$ half width of the flat. As in [1 - 3] we associate a cylindrical coordinate system $\mathrm{rOz}^{\prime}$ with a moving cylinder, axis $z$ coincides with the axle of the cylinder. We associate with a layer a fixed Cartesian coordinate system $x y z$ [5-7].

The stamp penetrates (Fig.1) an elastic layer at a speed $V_{T}(t),(0 \leq t \leq T)$ with initial value $V_{0}=V_{T}(0)$, where $T$ is the time of interaction of a stamp with a layer. We introduce dimensionless variables.

$$
\begin{gathered}
t^{\prime}=\frac{C_{0} t}{R}, x^{\prime}=\frac{x}{R}, z^{\prime}=\frac{z}{R}, u_{t}^{\prime}=\frac{u_{t}}{R}, \\
\sigma_{i j}^{\prime}=\frac{\sigma_{i j}}{K}, v_{T}^{\prime}=\frac{v_{T}}{C_{0}}, w_{T}^{\prime}=\frac{w_{T}}{R}, p^{\prime}=\frac{p}{K R}, \\
q^{\prime}=\frac{q}{K R}, M^{\prime}=\frac{M}{\rho R^{2}},(i, j=x, y, z),
\end{gathered}
$$

$$
\begin{gathered}
\beta^{2}=\frac{C_{S}^{2}}{C_{0}^{2}}=\frac{\mu}{K}, \alpha^{2}=\frac{C_{p}^{2}}{C_{0}^{2}}=\left(1+\frac{4 \mu}{3 K}\right), \\
C_{0}^{2}=\frac{K}{\rho}, b^{2}=\frac{\beta^{2}}{\alpha^{2}}=\frac{3 \mu}{3 K+4 \mu} .
\end{gathered}
$$

where $\rho, \mu, K, C_{p}$ and $C_{s}$ is the density, the displacement module, the volume deformation module and the velocity of the waves in the elastic layer.

The motion [1 - 3] of an elastic layer is described by scalar potentials pand $\psi$, which satisfy the wave equations [5-7]:

$$
\Delta \varphi=\frac{\partial^{2} \varphi}{\alpha^{2} \partial t^{2}}, \Delta \psi=\frac{\partial^{2} \psi}{\beta^{2} \partial t^{2}}, \Delta \equiv \frac{\partial^{2}}{\partial x^{2}}+\frac{\partial^{2}}{\partial y^{2}} .
$$

When problem solving an approach is used $[1-3]$, which makes it possible at the initial stage of penetration to identify the linear coordinates along the surface of the layer and body [5 - 7]. As a result, approximate ratios will be executed.

$$
r \approx \theta, \operatorname{ctg} \theta \approx 1 / \theta
$$

In the contact area, taking into account (1), there is a relationship between $u_{z}$ and pressure p.

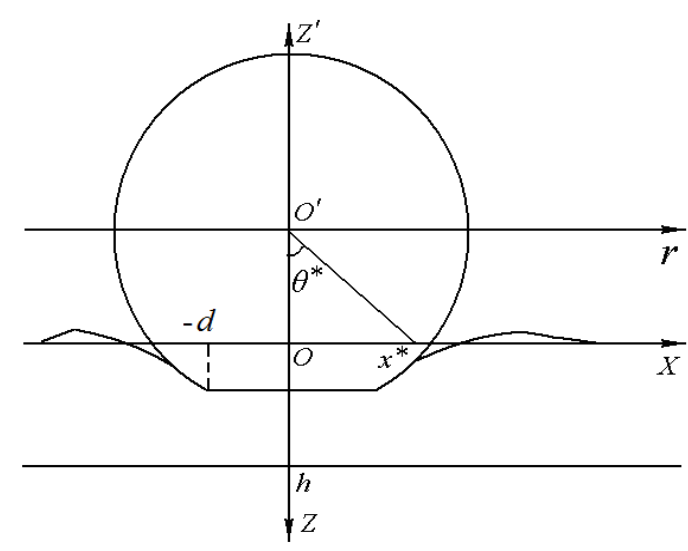

Fig.1. Scheme of the system stamp-layer

$$
u_{z}(t, x, 0)=w_{T}(t)-H(|x|-d) \times
$$




$$
\begin{gathered}
\times\left(1-\sqrt{1-(|x|-d)^{2}}\right), \\
w_{T}(t)=\int_{0}^{t} V(\tau) d \tau, p(t, x)=-\sigma_{z z}(t, x, 0),|x|<x^{*} .
\end{gathered}
$$

Linear zed boundary conditions are as follows:

$$
\begin{gathered}
\left.\frac{\partial u_{z}}{\partial t}\right|_{z=0} \equiv V(t, x)=v_{T}(t), \quad|x|<x^{*}(t), \\
\left.\sigma_{z z}\right|_{z=0}=0,|x|>x^{*}(t), \\
\left.\sigma_{z x}\right|_{z=0}=0,|x|<\infty .
\end{gathered}
$$

On the surface of the layer $z=h$ there are conditions of hard jamming.

For interaction time $0 \leq t \leq T$ select a rectangle $\quad\{|x| \leq l, 0 \leq z \leq h\}$, which is occupied by the medium, and the task of impact on the layer can be considered as a problem of impact on a rectangle. The width of the rectangle $l$ is chosen so that the perturbation waves do not reach its boundaries:

$$
|x|=l\left(l>\alpha\left(T-t_{0}\right)+x^{*}\left(t_{0}\right),\left.\frac{d x^{*}}{d t}\right|_{t=t_{0}}\right) \text {. }
$$

For certainty, we choose the condition of a smooth sliding contact on the lateral surface of the rectangle. Initial conditions of the problem are zero.

$$
\begin{aligned}
& \left.u_{x}\right|_{|x|=l}=0,\left.\quad \sigma_{z x}\right|_{|x|=l}=0, \\
& \left.\varphi\right|_{t=0}=\left.\frac{\partial \varphi}{\partial t}\right|_{t=0}=0,\left.\psi\right|_{t=0}=\left.\frac{\partial \psi}{\partial t}\right|_{t=0}=0 .
\end{aligned}
$$

The motion of a cylinder as a body outlines the second law of Newton

$$
M \frac{\partial^{2} w_{T}}{\partial t^{2}}=-F(t), V_{T}(0)=V_{0}, w_{T}(0)=0,
$$

where $F(t)$ - the reaction strength of an elastic layer, which is determined considering (2), (4) as an integral from pressure in the contact region:

$$
F(t)=2 \int_{0}^{x^{*}(t)} p(t, x) d x .
$$

The boundary of the contact area $x^{*}$, taking into account the motion of the particles of the medium and retarding the penetration of the cylinder in the elastic medium, is determined from the condition:

$$
\begin{gathered}
w_{T}(t)-u_{z}\left(t, x^{*}, 0\right)-H\left(\left|x^{*}\right|-d\right) \times \\
\times\left(1-\sqrt{1-\left(\left|x^{*}\right|-d\right)^{2}}\right)= \begin{cases}0, & |x| \leq x^{*}(t) \\
\varepsilon<0, & |x|>x^{*}(t) .\end{cases}
\end{gathered}
$$

Second problem. Its mathematical formulation is the same as in $[10,11,13,16$, 17]. Deformation of a beam sample in the form of a rectangle $\Sigma=L \times h$ $(-L / 2 \leq x \leq L / 2 ; 0 \leq y \leq h)$ is considered. The beam samples based on a completely rigid basis along $\{-L / 2 \leq x \leq L / 2 ; y=0\}$. The thickness of the sample is considered so large that it would be possible to use the dependences of the plane strain state.

On top of the body a completely hard impact or contacts with beam along the segment $\{|x| \leq d ; y=h\}$. Its effect on the body in the contact area will be replaced evenly distributed normal stress $-P$ which varies with time as a linear function $P=p_{01}+p_{02} \times(t / \Delta t-1), \quad$ where $\Delta t-$ increment of time.

Given the symmetry of the deformation process with respect to the line $x=0$, only the right part of the transverse section of the body is considered further (Fig.2).

As a result of the impact load we will consider that the material is elastic-plastic with strengthening and calculation of fields of stresses, deformations and their increments, in particular, increments of plastic deformation 
intensity $d \varepsilon_{i}^{p}$ and the parameter of the Odquist $\kappa=\int d \varepsilon_{i}^{p}$ will be carried out on the basis of numerical solution of the corresponding dynamic elastic-plastic problem.

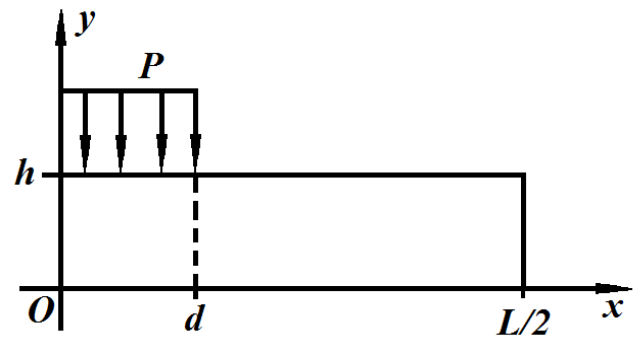

Fig.2. Scheme of the system stamp-layer. Second problem

When calculating the dynamic fields of stresses and deformations the interaction of wave fields, reflection from the boundary of the body were not taken into account.

The equations of motion for a plane problem are used

$$
\begin{aligned}
& \frac{\partial \sigma_{x x}}{\partial x}+\frac{\partial \sigma_{x y}}{\partial y}=\rho \frac{\partial^{2} u_{x}}{\partial t^{2}}, \\
& \frac{\partial \sigma_{x y}}{\partial x}+\frac{\partial \sigma_{y y}}{\partial y}=\rho \frac{\partial^{2} u_{y}}{\partial t^{2}}
\end{aligned}
$$

where $\rho$-material density.

The boundary conditions of the problem, which follow from the assumption that the region of application of the forces of the reaction of the supports is unaltered, as well as the determination of the supporting reactions have done using static methods, are written:

$$
\begin{aligned}
& x=0 ; \quad 0<y<B: \quad u_{x}=0, \sigma_{x y}=0 ; \\
& x=\frac{L}{2}, \quad 0<y<B: \quad \sigma_{x x}=0, \sigma_{x y}=0 ; \\
& y=0,0<x<\frac{L}{2}: u_{y}=0, \sigma_{x y}=0 ;
\end{aligned}
$$

$$
\begin{aligned}
& y=h, \quad 0<x<d: \quad \sigma_{y y}=-P, \sigma_{x y}=0 \\
& y=h, \quad d<x<\frac{L}{2}: \quad \sigma_{y y}=0, \sigma_{x y}=0 .
\end{aligned}
$$

Initial conditions are zero. In the basis of the defining relations of the mechanical model, the theory of no isothermal plastic flow of the medium with the strengthening under the condition of Huber-Mises fluidity [10, 11, 13, $16,17]$ was applied. The effects of creep and temperature expansion are neglected. Then, considering the components of the deformation tensor by the sum of the elastic and plastic components of it $[10,11,13,16$, 17], we obtain for them

$$
\begin{aligned}
& \varepsilon_{i j}=\varepsilon_{i j}^{e}+\varepsilon_{i j}^{p}, \quad \varepsilon_{i j}^{e}=\frac{1}{2 G} s_{i j}+K \sigma+\varphi_{1}, \\
& d \varepsilon_{i j}^{p}=s_{i j} d \lambda,
\end{aligned}
$$

here $s_{i j}=\sigma_{i j}-\delta_{i j} \sigma-$ components of the stress tensor deviator; $\delta_{i j}$ - a symbol of Kronecker; $G$ - displacement module; $K_{1}=(1-2 v) /(3 E) ; E$ - modulus of elasticity; $v$-Poisson's coefficient; $K=3 K_{1}$ - the volume compression module, which binds to the ratio $\varepsilon=K \sigma+\varphi_{1}$ volumetric expansion $3 \varepsilon$ (temperature expansion $\left.\quad \varphi_{1} \equiv 0\right)$; $\sigma=\left(\sigma_{x x}+\sigma_{y y}+\sigma_{z z}\right) / 3$-average tension; $d \lambda-$ some scalar function, which is determined by the condition of plasticity (the shape of the surface of the load) and in view of the above, its choice quadratic ally depends on the components of the deviant stress $s_{i j}[10,11$, $13,16,17]$. The material is strengthened with a strengthening factor $\eta_{*}[10,11,13,16,17]$ :

$$
\begin{gathered}
\sigma_{S}(T)=\sigma_{02}\left(T_{0}\right)\left(1+\frac{\kappa(T)}{\varepsilon_{0}}\right)^{\eta_{*}}, \\
\varepsilon_{0}=\frac{\sigma_{02}\left(T_{0}\right)}{E}, T_{0}=20^{\circ} \mathrm{C},
\end{gathered}
$$

where $\sigma_{S}(T)$ - the line of fluidity after strengthening the material at a temperature $T$. 


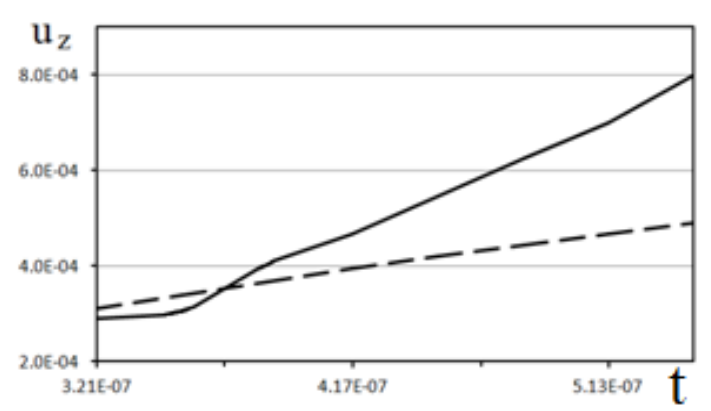

Fig. 3. The vector of the displacement component $u_{z}$

\section{SCHEME AND METHODS NUMERIC REALIZATION}

The scheme, methods of solving and numerical realization of the first problem are the same as in $[1,2]$ and for the second problem - are the same as in $[10,11,13,16$, 17]. The application of the finite difference method to the solution of wave equations is justified in [22] and ensure the accuracy of calculations with an error of not more than $O\left((\Delta x)^{2}+(\Delta y)^{2}+(\Delta t)^{2}\right)$.

As example an aluminum layer was chosen $\mu=0.3582 K$. The figures below represent the results corresponding to the calculation when $V_{0}=0.0002, \quad h / R=0.01, \quad M=0.001$, $l=0.6, \quad T=0.05, \quad h=0.4, \quad d=0.02$; $\Delta t=4.166667 \mathrm{E}-5$.

The results of the calculation for the second problem are obtained for the following parameters values: the coefficient of strengthening the material $\eta_{*}=0,05$; $L=600 \mathrm{~mm} ; \quad h=400 \mathrm{~mm} ; \quad d=2 \mathrm{~mm}$; $p_{01}=10.1 \mathrm{MPa} ; \quad p_{02}=4,04 \mathrm{MPa} ; \quad M=80$; $N=101$. The smallest step of the partition was near the upper surface and equaled $0,01 \mathrm{~mm}$, ( $\Delta x_{\min }=0,01 \mathrm{~mm} ; \Delta y_{\min }=0,01 \mathrm{~mm}$ (only the first three layers)), $T=50^{\circ}$.

In the elastic-plastic model, the axle $O y$ coincides with the axis $O z^{\prime}$. In Fig.3 shows the components of the displacement vectors $u_{z}$ in the first problem and $-u_{y}$ in the second are shown at the Fig. 3 and denoted by

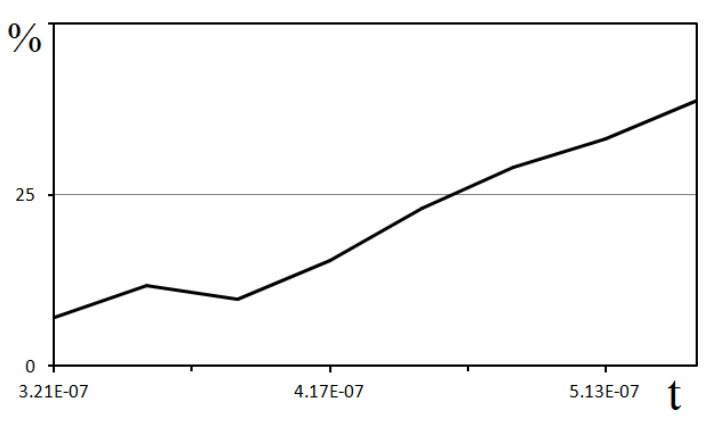

Fig. 4. Rejection of results

$u_{z}$. The components of vector displacements $u_{z}$ in the point $(0,0)$ in the center of the contact area for the first problem in the elastic model (dashed line) and at the point (0.01, 399.99) for the second problem in the elasticplastic formulation (solid line) were compared.

The percentage of rejection of the displacement values $u_{z}$ received for the first and second tasks is shown at the Fig.4. A period has been found for which this deviation does not exceed $8 \%$.

\section{CONCLUSIONS}

The results of solving plane problems of the impact of a circular cylinder with a flat in an elastic model and a non-stationary interaction in an elastic-plastic mathematical setting at the elastic stage coincide well. The use of elastoplastic formulation makes it possible:

1. Determine the stress-strain state at the points determined by the grid of the breakdown of the calculated region, and not only on the surface.

2. Give a plausible description of the development of plastic deformations. The step corresponding to plasticity is the continuation of the elastic stage.

3. Authentically determine the destruction toughness $K_{\text {Ic }}$.

4. To verify the solving of problems in the elastic-plastic formulation of the first steps in time, when the deformation process is elastic, it is convenient to use the solution of the corresponding elastic problem. 


\section{REFERENCES}

1. Bogdanov V.R., 2017. Impact of a hard cylinder with flat surface on the elastic layer. Underwater Technologies, Vol.05, 8-15.

2. Bogdanov V.R., Lewicki H.R., Pryhodko T.B., Radzivill O.Y., Samborska L.R., 2009. The planar problem of the impact shell against elastic layer. Visnyk NTU, Kyiv, No.18, 281292 (In Ukrainian).

3. Kubenko V.D., Bogdanov V.R., 1995. Planar problem of the impact of a shell on an elastic half-space. International Applied Mechanics, 31, No.6, 483-490.

4. Kubenko V.D., Bogdanov V.R., 1995. Axisymmetric impact of a shell on an elastic halfspace. International Applied Mechanics, 31, No.10, 829-835.

5. Kubenko V.D., Popov S.N., Bogdanov V.R., 1995. The impact of elastic cylindrical shell with the surface of elastic half-space. Dop. NAN Ukrainy, No.7, 40-44 (in Ukrainian).

6. Kubenko V.D., Popov S.N., 1988. Plane problem of the impact of hard blunt body on the surface of an elastic half-space. Pricl. Mechanika, 24, No.7, 69-77 (in Russian).

7. Popov S.N., 1989. Vertical impact of the hard circular cylinder lateral surface on the elastic half-space.Pricl. Mechanika, 25, No.12, 41-47 (in Russian).

8. Bogdanov V.R., Sulim G.T., 2016. Determination of the material fracture toughness by numerical analysis of 3D elastoplastic dynamic deformation. Mechanics of Solids, 51(2), 206-215; DOI 10.3103/S0025654416020084.

9. Bogdanov V.R., 2015. A plane problem of impact of hard cylinder with elastic layer. Bulletin of University of Kyiv: Mathematics. Mechanics, No.34, 42-47 (in Ukrainian).

10.Bogdanov V.R., Sulym G.T., 2013. Plain deformation of elastoplastic material with profile shaped as a compact specimen (dynamic loading). Mechanics of Solids, May, 48(3), 329336; DOI 10.3103/S0025654413030096.

11.Bogdanov V.R., Sulym G.T., 2013. A modeling of plastic deformation's growth under impact, based on a numerical solution of the plane stress deformation problem. Vestnik Moskovskogo Aviatsionnogo Instituta, Vol.20, Iss.3, 196-201 (in Russian).

12.Bogdanov V.R., 2009. Three dimension problem of plastic deformations and stresses concentration near the top of crack. Bulletin of
University of Kyiv: Series: Physics \& Mathematics, No.2, 51-56 (in Ukrainian).

13.Bogdanov V.R., Sulym G.T., 2012. The plane strain state of the material with stationary crack with taking in account the process of unloading. Mathematical Methods and Physicomechanical Fields, Lviv 55, No.3, 132-138 (in Ukrainian).

14.Bogdanov V.R., Sulym G.T., 2010. The crack growing in compact specimen by plastic-elastic model of planar stress state. Bulletin of University of Kyiv: Series: Physics \& Mathematics, No. 4, 58-62 (In Ukrainian).

15.Bogdanov V.R., Sulym G.T., 2010. The crack clevage simulation based on the numerical modelling of the plane stress state. Bulletin of University of Lviv: Series: Physics \& Mathematics, No. 73, 192-204 (in Ukrainian).

16.Bohdanov V.R., Sulym G.T., 2011. Evaluation of crack resistance based on the numerical modelling of the plane strained state. Material Science, 46, No.6, 723-732.

17.Bogdanov V.R., Sulym G.T., 2011. The clevage crack simulation based on the numerical modelling of the plane deformation state. Scientific collection Problems of Calculation Mechanics and Constructions Strength, Dnepropetrovsk, No.15, 33-44 (in Ukrainian).

18.Bogdanov V.R., Sulym G.T., 2010. Destruction toughness determination based on the numerical modelling of the three dimension dynamic problem. International scientific collection Strength of Machines and Constructions, Kyiv, No.43, 158-167 (in Ukrainian).

19.Bogdanov V.R., Sulym G.T., 2012. A three dimension simulation of process of growing crack based on the numerical solution. Scientific collection Problems of Calculation Mechanics and Constructions Strength, Dnepropetrovsk, No.19, 10-19 (in Ukrainian).

20.Bogdanov V.R., Sulym G.T., 2012. The crack clevage simulation in a compact specimen based on the numerical modeling of the three dimension problem. Scientific collection Methods of Solving Applied Problems in Solid Mechanics, Dnepropetrovsk, No.13, 60-68 (in Ukrainian).

21.Bogdanov V.R., 2011. About three dimension deformation of an elastic-plastic material with the profile of compact shape. Theoretical and Applied Mechanics, Donetsk, No.3 (49), 51-58 (in Ukrainian).

22.Zjukina E.L., 2004. Conservative difference schemes on non-uniform grids for a twodimensional wave equation. Trudy 
matematicheskogo centra imeni N.I. Lobachevskogo, Kazan', T.26, 151-160 (in Russian).

23.Weisbrod G., Rittel D., 2000. A method for dynamic fracture toughness determination using short beams. International Journal of Fracture, 104, 89-103.

\section{Удар кругового цилиндра с лыской по упругому слою}

\section{Владислав Богданов}

Аннотация. Задачи ударного нагружения твердых деформируемых тел остаются актуальными и исследуются в самых разных постановках. В работе проводиться сравнение результатов решения двух плоских задач: удара кругового цилиндра с плоской площадкой параллельной оси цилиндра (лыской) с упругим слоем и второй - о плоском деформированном состоянии при нестационарном взаимодействии кругового цилиндра с лыской с упругим слоем в чисто упругой и упругопластической математических постановках соответственно. Первоначальный контакт происходит по плоскости лыски. Показано хорошее совпадение результатов второй задачи на начальном упругом этапе с результатами первой задачи.
Разработан новый подход решения задач удара и нестационарного взаимодействия в упругопластической постановке. Численное решение получено с использованием схемы метода конечных разностей. Использование упругопластической постановки дает возможность: 1) определить напряженнодеформированное состояние в точках, определяемых сеткой разбиения расчетной области, а не только на поверхности; 2) дать достоверное описание развития пластических деформаций - этап, отвечающий пластичности, является продолжением упругого этапа; 3) достоверно определить вязкость разрушения. Разработана методика расчета полей пластических деформаций и вязкости разрушения материала с использованием решения динамических плоских задач о напряженно деформированном состоянии в упругопластической постановке с учетом возможной разгрузки материала. 4. Для верификации решения задач в упруго-пластической постановке для первых шагов по времени, когда процесс деформации является упругим, удобно использовать решение соответствующей упругой задачи.

Ключевые слова: удар, упругий, упругопластический, слой, плоская задача, жесткий цилиндр. 